This item was submitted to Loughborough's Research Repository by the author.

Items in Figshare are protected by copyright, with all rights reserved, unless otherwise indicated.

\title{
Hybrid anode concrete corrosion protection - independent study
}

\section{PLEASE CITE THE PUBLISHED VERSION}

https://doi.org/10.1680/jcoma.16.00024

\section{PUBLISHER}

(c) Institution of Civil Engineers (ICE)

\section{VERSION}

AM (Accepted Manuscript)

\section{PUBLISHER STATEMENT}

This work is made available according to the conditions of the Creative Commons Attribution-NonCommercialNoDerivatives 4.0 International (CC BY-NC-ND 4.0) licence. Full details of this licence are available at: https://creativecommons.org/licenses/by-nc-nd/4.0/

\section{LICENCE}

CC BY-NC-ND 4.0

\section{REPOSITORY RECORD}

Dodds, Wayne J., Christian Christodoulou, and Chris I. Goodier. 2019. "Hybrid Anode Concrete Corrosion Protection - Independent Study". figshare. https://hdl.handle.net/2134/22886. 


\title{
Hybrid Anode Concrete Corrosion Protection - An Independent Appraisal
}

\author{
Dodds, $\mathrm{W}^{1,2}$, Christodoulou, $\mathrm{C}^{1}$, Goodier, C.I ${ }^{2}$ \\ ${ }^{1}$ AECOM Birmingham, ${ }^{2}$ Loughborough University
}

ABSTRACT: This study was the first of its kind which looked at long term performance of hybrid anode systems in reinforced concrete while also using a holistic approach to corrosion risk assessment. An independent appraisal of the site performance of DuoGuard ${ }^{\mathrm{TM}}$ Hybrid Anode ${ }^{\mathrm{TM}}$ systems was conducted on six bridges structures between 2013 and 2014. The hybrid systems had been installed on six reinforced concrete bridge structures in the UK between 2006 and 2013. The aim of the study was to investigate the efficiency of current design approach to meet the residual service life when the anodes are operating in the galvanic phase. This was achieved by analysing data on the general condition of the structures, the ongoing performance of the installed hybrid anodes, and assessing the overall corrosion risk of the structures.

It was found that the six structures were generally in good condition, with low associated corrosion risks. More specifically, the areas protected by the hybrid anode systems had no associated defects or evidence of corrosion. This is a positive finding for the wider implementation of hybrid anode systems as an alternative corrosion management technique. The reinforcement in the protected areas remained predominately in a passive condition, with calculated corrosion rates below the ISO 12696:2012 recommended threshold of $2 \mathrm{~mA} / \mathrm{m}^{2}$. On some occasions the corrosion rates exceeded the recommended threshold; in these instances, corrosion risk was assessed by analysing the trends of long term monitoring data (e.g. open steel circuit potentials) for signs of corrosion initiation. This study also makes recommendations on aspects of design approach in order to improve redundancy, functionality and robustness of hybrid anode systems.

Keywords: Reinforced concrete, corrosion, hybrid anodes, electrochemical treatments.

\section{INTRODUCTION}

\subsection{HYBRID CORROSION PROTECTION TECHNOLOGY}

Cathodic protection of reinforced concrete structures is a well-established method of preventing the initiation of corrosion. Impressed current cathodic protection (ICCP) systems has been used on concrete structures for more than 30 years and pass a protective current to the steel reinforcement without sacrificing the installed anode [1,2]. Galvanic technology conversely has been available for around 200 years and is based on the principle of a more active metal being sacrificed in order to create a cathode at the reinforcing steel [3].

DuoGuard ${ }^{\mathrm{TM}}$, is a discrete zinc anode system that is installed into pre-drilled cavities within reinforced concrete (Figure 1). It is a relatively new development in cathodic protection, as it combines both an impressed and galvanic system to arrest ongoing corrosion and prevent future initiation. Initially, the system is connected to a temporary, constant voltage power supply, typically for a period of at least one week, depending on the type of reinforcement (e.g. mild steel or prestressed), to deliver a charge to the reinforcing steel [4-8]. This initial impressed treatment phase (minimum 50kC of charge) re-passivates the reinforcement by means of generating a reservoir of alkali at the steel concrete interface [8-12]. The hybrid anode is then disconnected from the temporary power supply and connected directly to the steel reinforcement, creating a galvanic cell, similar to a battery. This latter treatment phase continues for the remainder of the anodes' working life and provides a relatively low current to the steel reinforcement to maintain steel passivity [6, 13-16].

The hybrid anode system is installed at a spacing dependent upon the steel density (per $\mathrm{m}^{2}$ of concrete), and is connected in series with insulated titanium wire. Different sizes of anode are available and are named based on the expected charge output during the anode's life (e.g. D350 and D500 anodes relate to an output of $350 \mathrm{kC}$ and $500 \mathrm{kC}$ respectively).

The hybrid technology offers the same advantages of a galvanic system, in that little or no maintenance is required throughout its design life cycle, and no permanent power supply needs to be installed as part of the works; while also packing the corrosion arrest power traditionally associated with a full ICCP system [4, 6-8]. The system design can allow for an additional impressed current phase $(50 \mathrm{kC})$ to be implemented at a later 
stage in the structure's life if any corrosion activity is detected through monitoring. This provides the benefit of extending the life of repaired areas by re-establishing steel passivity if required.

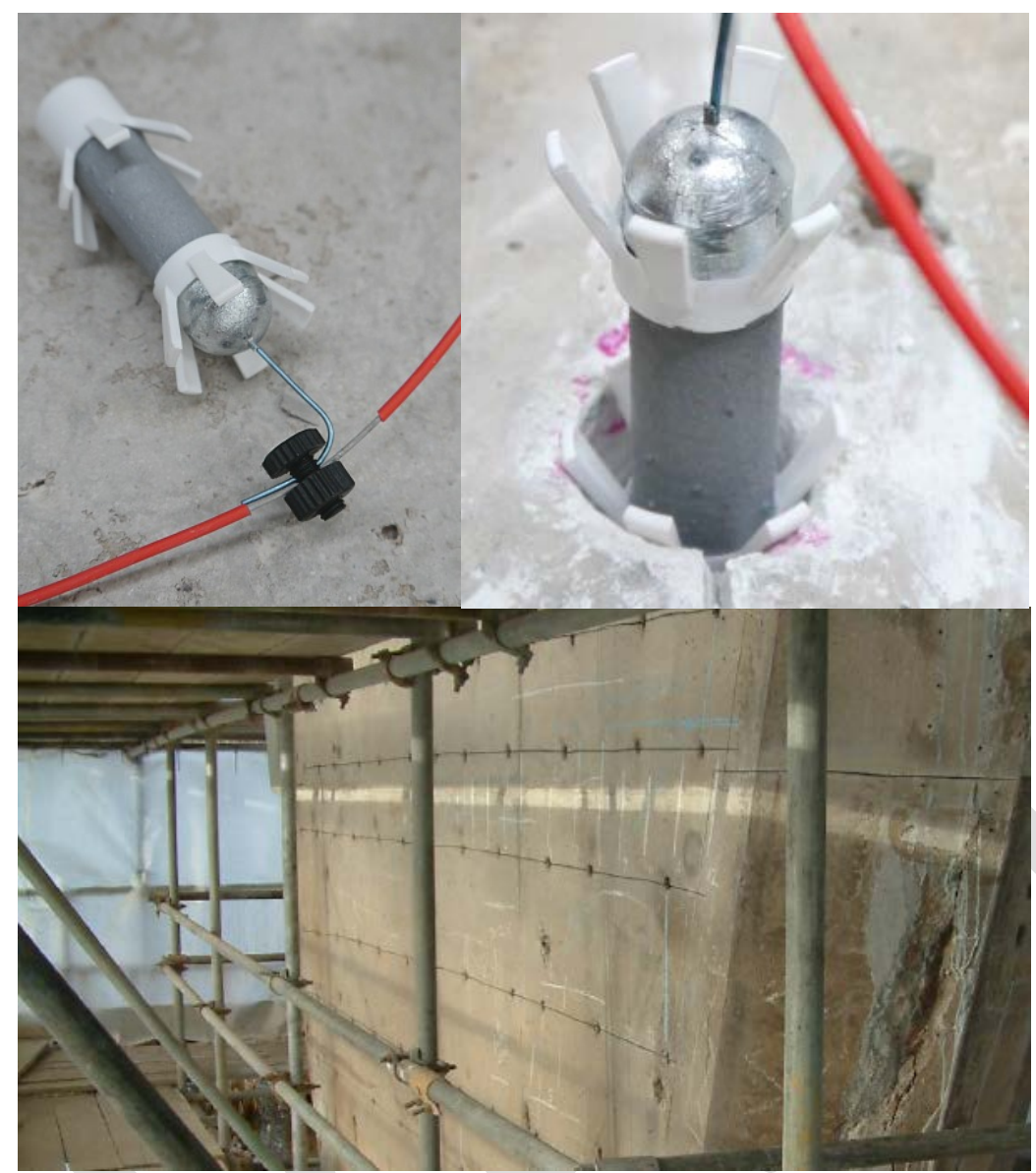

Figure 1 - Installation of hybrid anode system to typical reinforced concrete pier [17]

Hybrid anodes are usually designed to provide a residual service life of 30-50 years based on an expected current demand from the surrounding reinforcing steel in a structure, similar to that of galvanic technology. ISO 12696:2012 acknowledges that hybrid and galvanic anodes may not necessarily meet the performance criteria set out in the standard [18], as these are recognised as empirical criteria (i.e. not mathematically derived) of accepted performance of ICCP systems. Hybrid anodes' current tends to fluctuate with the changing risk of corrosion initiation, commonly referred to as the 'responsive behaviour' [13]. This has resulted to some views within industry as to the accuracy of designs to meet the residual service life when the anodes are operating within the galvanic phase. Instead of assessing performance against absolute values, ISO 12696:2012 [18] acknowledges that a holistic approach to the overall condition and corrosion risk assessment of the structure should be adopted for hybrid and galvanic anodes.

\subsection{PERFORMANCE EVALUATION}

The performance criteria for cathodic protection systems require a positive depolarisation shift of steel potential by $100 \mathrm{mV}$ over a period of 24 hours or a depolarisation greater than $150 \mathrm{mV}$ more over an extended period of time. This potential shift has been empirically developed over time and later adopted within the ISO standard as an absolute value. Research into the behaviour of galvanic and hybrid systems has shown that the $100 \mathrm{mV}$ potential shift is not always achieved in benign environments and when the risk of corrosion has been reduced by the anode system itself $[6,7,14]$. It is for this reason that ISO 12696:2012 allows the use of alternative criteria to assess cathodic protection systems, such as corrosion rates, with values less than $2 \mathrm{~mA} / \mathrm{m}^{2}$ indicating passive steel [18]. The corrosion rate can be determined using an established mathematical model, the Butler-Volmer equation (Eqn. 1). A corrosion rate of this magnitude $\left(2 \mathrm{~mA} / \mathrm{m}^{2}\right)$ equates to a steel section loss of approximately $1 \mathrm{~mm}$ over 500 years, which is a particularly stringent value for a reinforced concrete structure that has a service life of 50-100 years. Christodoulou et al, found that the $2 \mathrm{~mA} / \mathrm{m}^{2}$ threshold is associated with benign environmental conditions and steel passivity when assessing the 
performance of impressed current cathodic protection systems [19]. A falling trend in corrosion rate combined with a rising trend in open circuit steel potential is also a sign that steel passivity is being achieved [18].

$$
i_{c o r r}=\frac{i_{a p p l}}{\left(\exp \left(\frac{2.3 \Delta \mathrm{E}}{\beta_{c}}\right)-\exp \left(-\frac{2.3 \Delta \mathrm{E}}{\beta_{a}}\right)\right)}
$$

\subsection{AIM OF THE STUDY}

The overarching aim of this study was to determine the effectiveness of hybrid anode systems at providing sufficient protection against the initiation of corrosion and also the performance of the oldest hybrid anode installations in order to examine their long term performance using a holistic condition and corrosion risk assessment as described by ISO 12696:2012 [18].

To achieve this, six bridge structures on which DuoGuard ${ }^{\mathrm{TM}}$ Hybrid Anode ${ }^{\mathrm{TM}}$ systems were installed around the UK between 2006 and 2013, in varying locations and climatic conditions, were examined. These are the following:

a) Laverock Hall, Newcastle, Tyne and Wear

b) Whiteadder, Berwick, Northumberland

c) Storth Lane, South Normanton, Derbyshire

d) Kyle of Tongue, Achuvoldrach, Highland

e) M69 Junction 2, Huncote, Leicestershire

f) Paston Interchange, Peterborough, Cambridgeshire

\section{STRUCTURES AND INSTALLATION}

The hybrid anode system was installed on six reinforced concrete bridge structures between 2006 and 2013. An overview of each structure is detailed below (Figure 2):

System (a): Laverock Hall, Newcastle (2006) - Laverock Hall overbridge was constructed in two halves for the Northbound and Southbound carriageways. The two $43 \mathrm{~m}$ bridges form part of the A189 carrying traffic over the A1061 (Figure 2a). Two reinforced concrete abutments are located at each end of the structure. Prior to repair works in March 2006, the bridge exhibited areas of substantial spalling and delamination to the piers, due to chloride ingress from leaking of the deck joints. Concrete repairs were undertaken to areas of significant corrosion damage, with DuoGuard ${ }^{\mathrm{TM}} 500$ anodes installed in the reinforced concrete abutments and piers, based on a design life of 30 years where significant levels of chloride content were measured. This was the world's first application of DuoGuard ${ }^{\mathrm{TM}}$ technology. Data logging equipment was installed to allow remote monitoring of the structure. The reinforced concrete abutments and piers received an additional waterproofing coating.

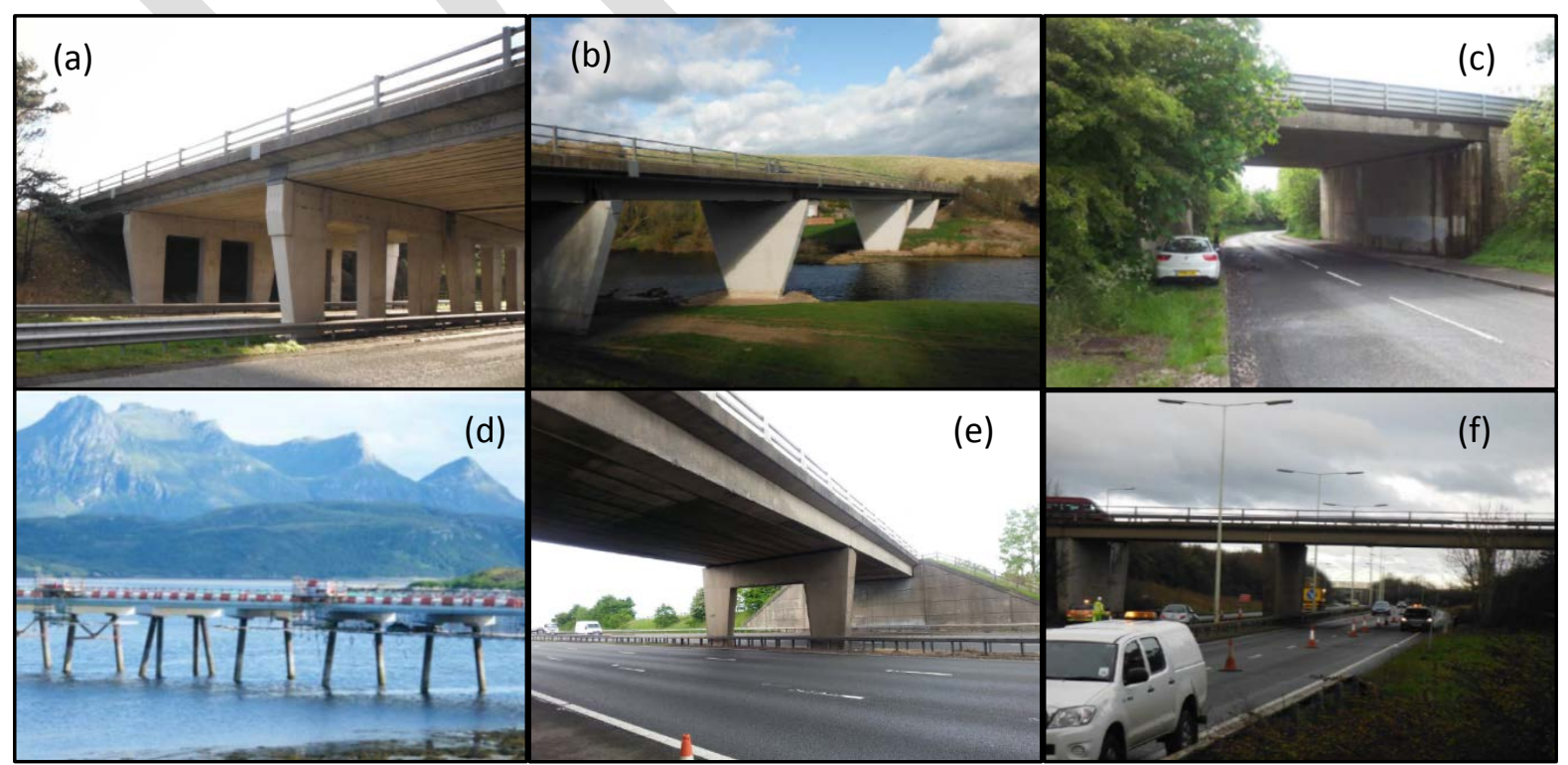

Figure 2 - Bridge structures with installed hybrid anode systems; (a) Laverock Hall, (b) Whiteadder, (c) Storth Lane, (d) Kyle of Tongue, (e) M69 Junction 2, (f) Paston Interchange 
System (b): Whiteadder, Berwick (2007) - This 90m long bridge forms part of the B6461 carrying traffic over the Whiteadder Water at Canty, near Paxton (Figure 2b). It opened in 1973 and is constructed from four steel girders supported on bearings directly above reinforced concrete piers. Prior to repair works the bridge exhibited areas of substantial spalling and delamination to the piers, due to chloride ingress from leaking of the deck joints. DuoGuard ${ }^{\mathrm{TM}} 500$ anodes were installed across the entire face of the four reinforced concrete piers to achieve a design life of 30 years. The piers also received additional protection in the form of a waterproof coating. Data logging equipment was installed on the bridge to allow remote monitoring of the structure [6].

System (c): Storth Lane, South Normanton (2007) - The bridge carries the A38 dual carriageway over Storth Lane in Derbyshire (Figure 2c). The single span structure is constructed from simply supported prestressed beams spanning between the two reinforced concrete abutments. DuoGuard ${ }^{\mathrm{TM}} 500$ anodes were installed along a single row in both bridge abutments, approximately $400 \mathrm{~mm}$ below the bearing shelf, to prevent further corrosion damage from the leaking bridge joints and to achieve a design life of 25 years. No major repair works were conducted on this bridge. Remote monitoring is not available at this site and readings have to be taken from the monitoring enclosure itself.

System (d): Kyle of Tongue, Achuvoldrach (2011) - The 183m long bridge forms part of a causeway carrying the A838 over the Kyle of Tongue estuary on the North coast of Scotland (Figure 2d). The bridge was fully refurbished following reports of high chloride concentrations due to the exposure in a marine environment and de-icing salts used on the bridge deck during the winter months. DuoGuard ${ }^{\mathrm{TM}} 175$ anodes were installed in localised repair areas and was the first time the technology was implemented in prestressed concrete beams with a design life of 30 years. In this particular occasion, the design required steel potentials to be maintained more positive than $-900 \mathrm{mV}$, during the energisation process, to prevent hydrogen embrittlement of the prestressed strands. Remote monitoring was installed due to the site location. A detailed review of the hybrid system at Kyle of Tongue has been conducted previously by Christodoulou et al $[7,8]$.

System (e): M69 Junction 2, Huncote (2012) - The two bridge structures at Junction 2 and the bridge North of Huncote village are situated on the M69 motorway in Leicestershire (Figure 2e). The three structures consist of simply supported prestressed beams spanning between the North and South abutments with an intermediate pier and supporting columns. Concrete repairs and hybrid anode installation was carried out to three abutments along the Westbound carriageway (one for each structure) following inspection reports which identified corrosion activity and significant chloride levels. DuoGuard ${ }^{\mathrm{TM}} 750$ anodes were installed in a single row along the length of all three abutments $200 \mathrm{~mm}$ below the bearing shelf to achieve a design life of 25 years. The anodes are separated into two individual zones per abutment and wired back to a centrally mounted junction box. Remote monitoring is not available at this site and readings have to be taken from the monitoring enclosure itself.

System (f): Paston Interchange, Peterborough (2013) - The two 41m long bridges of the A47 Paston Interchange both support a dual carriageway roundabout above the A15, located at Junction 20 (Figure $2 \mathrm{f}$ ). The four-span bridge consists of 27 simply supported prestressed beams spanning between 3 reinforced concrete crosshead beams and supporting columns. DuoGuard ${ }^{\mathrm{TM}} 350$ hybrid anodes were installed on the outer piers of both bridge structures, to both the traffic and verge faces, to prevent further corrosion damage following concrete repairs. The system was designed to achieve a 25 year design life. Remote monitoring is not available at this site and readings have to be taken from the monitoring enclosure itself.

\section{METHODOLOGY}

A desk study was initially conducted including a review of previous principal inspection reports, existing monitoring data, and as-built drawings, where available. Each structure was visually inspected to determine the condition of the reinforced concrete structures and to confirm details of both the structure and the installed hybrid anode system.

Steel potential readings were recorded before and after a 24 hour depolarisation period, where possible. Corrosion rates were subsequently calculated by means of the polarisation resistance method to determine the effectiveness of the hybrid systems in preventing the initiation of corrosion. The Butler-Volmer equation (Eqn. 1) is an established method of calculating corrosion rates from depolarisation data and has previously been used to report on the performance of cathodic protection systems $[4,5,7,14,20]$. The equation uses the 
recorded depolarisation shift and local applied current density, in an area of known steel density, to provide an indication of overall corrosion current density (e.g. corrosion rate) which is an indication of the condition of the reinforcement. The anodic ( $\beta a)$ and cathodic $(\beta c)$ Tafel slopes were set at $120 \mathrm{mV}$ [14].

The corrosion rate for each of the structures was assessed against the criteria for cathodic protection systems as laid out in ISO 12696:2012 [18], whereby a corrosion rate of less than $2 \mathrm{~mA} / \mathrm{m}^{2}$ indicates passive steel conditions. Where possible, the change in corrosion rates was also assessed against the trend of open circuit steel potential $[6,18]$.

\section{ANALYSIS}

Overall, the six structures were found to be in good condition following refurbishment works with minor site specific defects as summarised in Table 1.

As the hybrid systems were installed at different times between 2006 and 2013, the extent of record monitoring data varies. The calculated corrosion rates and subsequent corrosion risk assessments are summarised for each structure below.

Table 1 - Inspection Summary

\begin{tabular}{|l|c|l|}
\hline Bridge Structure & Inspection Date & Notes \\
\hline (a) Laverock Hall & March 2014 & $\begin{array}{l}\text { No visible defects were noted to the reinforced concrete piers. Water } \\
\text { staining was observed at high level indicating that the bridge joints } \\
\text { are still leaking. }\end{array}$ \\
\hline (b) Whiteadder & March 2014 & $\begin{array}{l}\text { No visible defects were noted to the reinforced concrete piers. Water } \\
\text { and rust staining observed on the piers from the primary steel girders } \\
\text { due to water ingresses through the deck joints. }\end{array}$ \\
\hline (c) Storth Lane & May 2014 & $\begin{array}{l}\text { Significantly more water ingress was observed on the South } \\
\text { abutment compared to the North abutment. No defects were noted } \\
\text { within the area of influence of the hybrid CP system. }\end{array}$ \\
\hline (d) Kyle of Tongue & February 2013 & $\begin{array}{l}\text { No signs of corrosion were found. Repairs to prestressed beams were } \\
\text { generally in good condition with no evidence of delamination or } \\
\text { spalling. No faults were identified with the hybrid CP system [4, 5]. }\end{array}$ \\
\hline (e) M69 Junction 2 & May 2014 & $\begin{array}{l}\text { No signs of corrosion were found. Small amounts of water ingress } \\
\text { were observed from the carriageway above across all three } \\
\text { abutments. No defects were noted within the area of influence of the } \\
\text { hybrid CP system. }\end{array}$ \\
\hline $\begin{array}{l}\text { (f) Paston } \\
\text { Interchange }\end{array}$ & January 2014 & $\begin{array}{l}\text { No signs of corrosion were found. No defects were noted within the } \\
\text { area of influence of the hybrid CP system. Water ingress was } \\
\text { observed from the carriageway above. }\end{array}$ \\
\hline
\end{tabular}

System (a): The corrosion rate for the pier beam has generally remained significantly below the $2 \mathrm{~mA} / \mathrm{m}^{2}$ recommended value for passive steel (Figure 3). On two occasions, a higher corrosion rate was measured for the pier column; however, this has since reduced back below the threshold value, showing that the anode has responded to the risk of corrosion initiation.

The two occasions where the corrosion rate increased above the $2 \mathrm{~mA} / \mathrm{m}^{2}$ threshold does not necessarily indicate a non-compliant system. The corrosion rate calculated at these two occasions equates to a reinforcing steel section loss of approximately $3.5 \mathrm{~mm}$ and $2.2 \mathrm{~mm}$ respectively, over a period of 1000 years, which is considered to be structurally negligible. 


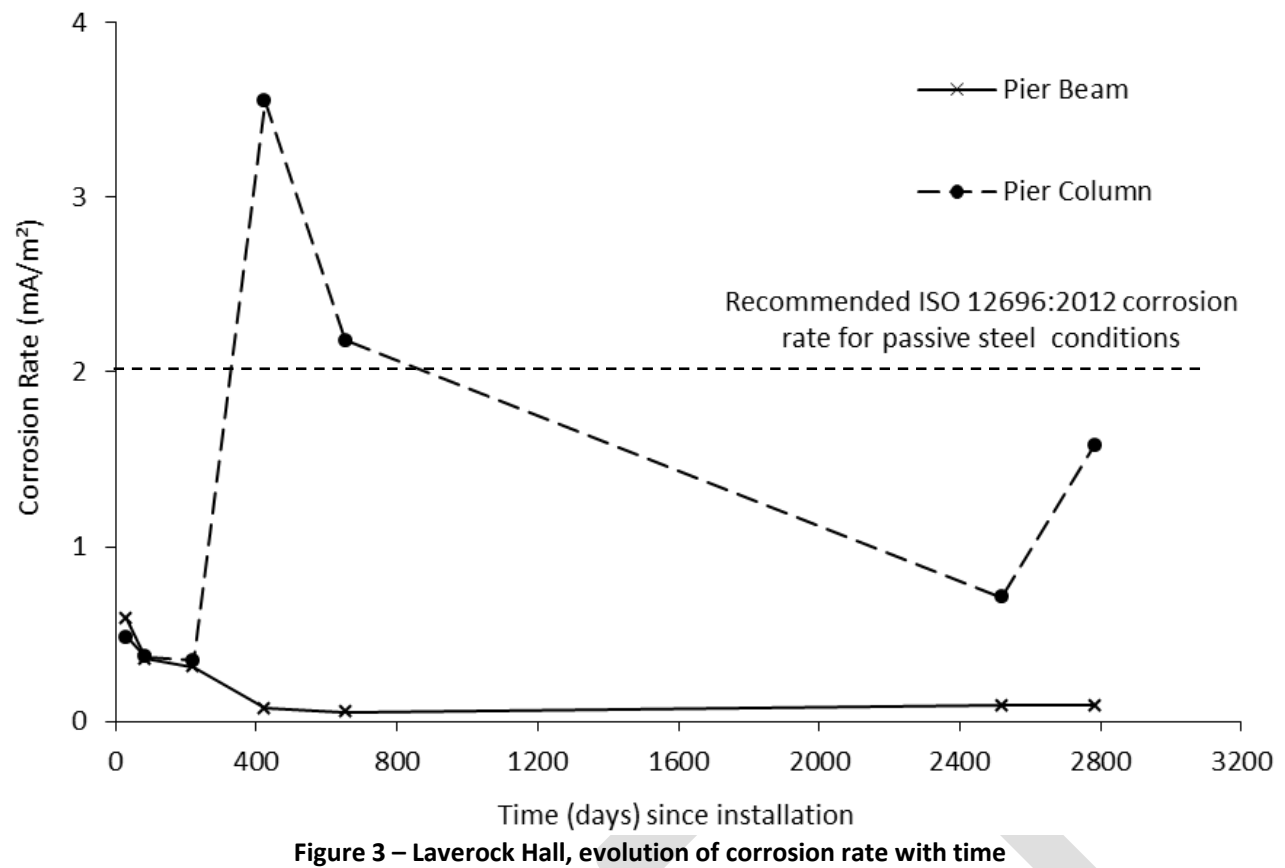

Furthermore, a review of the steel 'on' potential values, indicates that generally they have increased over time which suggests overall steel passivity (Figure 4).

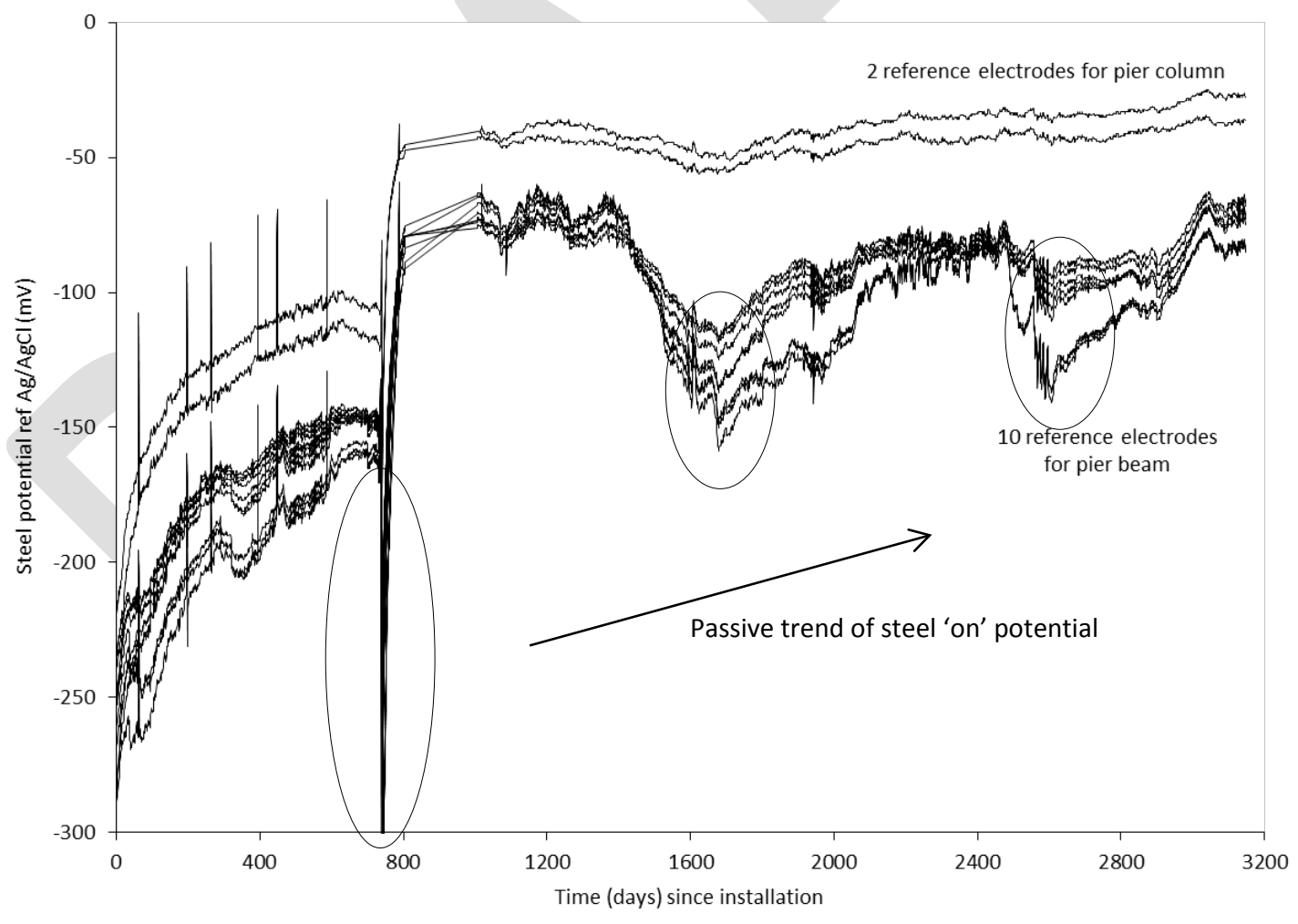

Figure 4 - Laverock Hall, evolution of steel potential over time

The sudden changes in 'on' potential readings observed at approximately 750, 1700 and 2550 days (identified in Figure 4) can be associated with changes in the environmental conditions due to wetting of the piers from the carriageway above. In these instances the hybrid anodes have responded effectively by providing a higher current to overcome the increased risk of corrosion [13]. The general trend of increasing steel potential with time, combined with the relatively low equivalent section losses and visual inspection details suggests this structure has a low risk of corrosion initiation. 
System (b): The value of corrosion rate for the upper anode zone has remained below the threshold value of $2 \mathrm{~mA} / \mathrm{m}^{2}$ since the installation of the hybrid system in 2007 , indicating that the steel has remained passive. In contrast, the values for the lower anode zone have fluctuated with time (Figure 5).

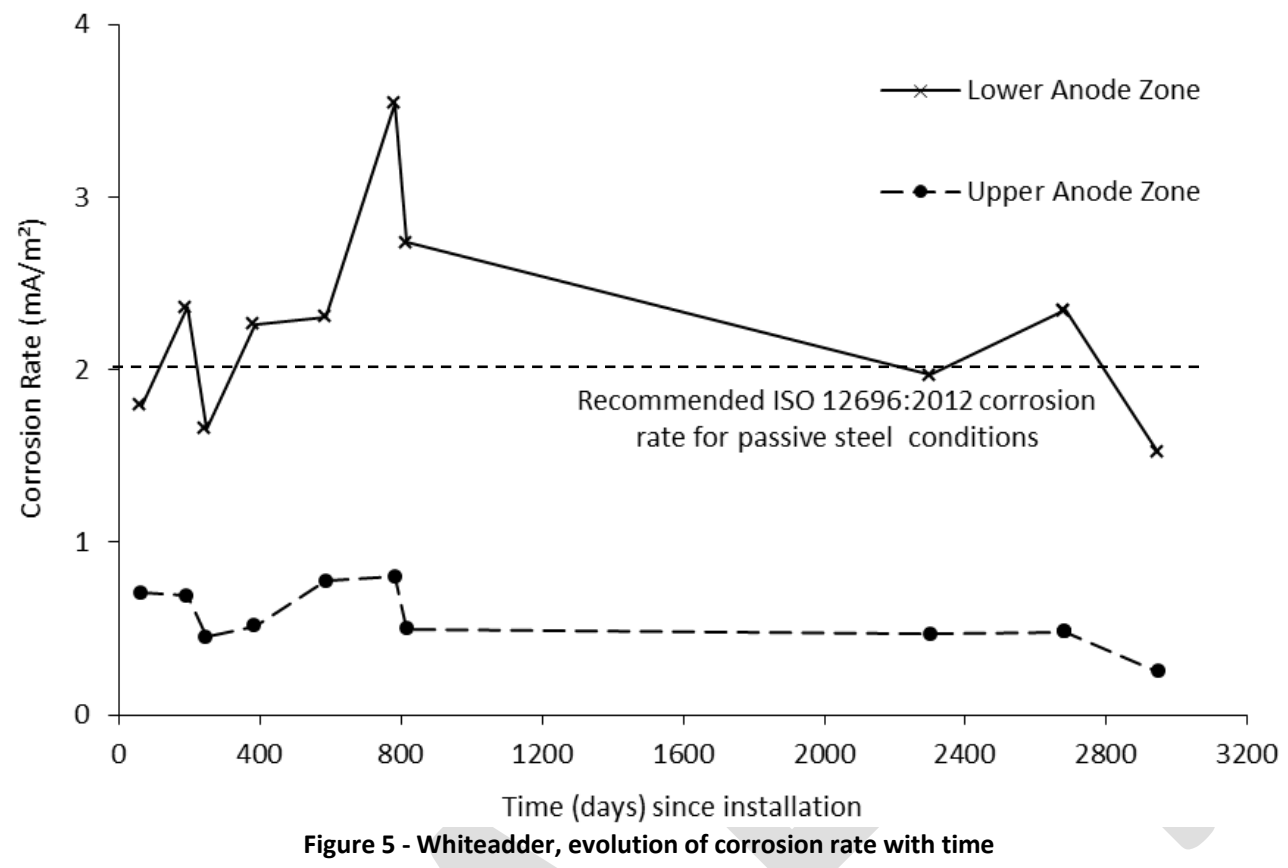

The corrosion rate for the lower anode zone has largely remained above the recommended threshold, although it is acknowledged that there are only a handful of available readings. The maximum corrosion rate calculated since installation is $3.5 \mathrm{~mA} / \mathrm{m}^{2}$ which equates to a reinforcing steel section loss of approximately $3.5 \mathrm{~mm}$ over a period of 1000 years, which is again considered to be negligible when compared to a 120 year design life of a bridge structure.

The monitoring data also shows that the current afforded by the anodes is higher for the lower anode zone (Table 2), which is most likely due to water ingress from the adjacent river. The current in the upper zone is significantly lower throughout which suggest that the concrete is much more dry. The current for both the upper and lower anode zone is decreasing with time which suggests that the steel reinforcement is gradually becoming more passive, as less protective current is required. The lower zone current has decreased at a more substantial rate, as the possibility of corrosion initiation is reduced in that area. The passivity of steel reinforcement for both zones is confirmed by the fact that the steel 'on' potential has been increasing towards move positive values for all monitored areas (Figure 6).

Table 2 - Whiteadder, Development of monitoring zone currents from background monitoring data

\begin{tabular}{|l|c|c|c|c|c|}
\hline Date & $08 / 04 / 2009$ & $12 / 05 / 2009$ & $04 / 06 / 2013$ & $20 / 06 / 2014$ & $12 / 03 / 2015$ \\
\hline Upper Zone $(\mathrm{mA})$ & 0.36 & 0.30 & 0.18 & 0.18 & 0.08 \\
\hline Lower Zone $(\mathrm{mA})$ & 2.24 & 1.95 & 1.25 & 0.92 & 0.48 \\
\hline
\end{tabular}

Similar to system (a), the sudden changes in 'on' potential readings observed at regular intervals (identified in Figure 6) are attributed to flooding of the river. In these instances the hybrid anodes have responded effectively by providing a much higher current to overcome the increased risk of corrosion [13]. Based on the magnitude of the calculated corrosion rate and the equivalent reinforcing steel section loss, and the passive trend of both the measured output currents and steel 'on' potentials, it is anticipated that the structure has a low risk of corrosion initiation. 


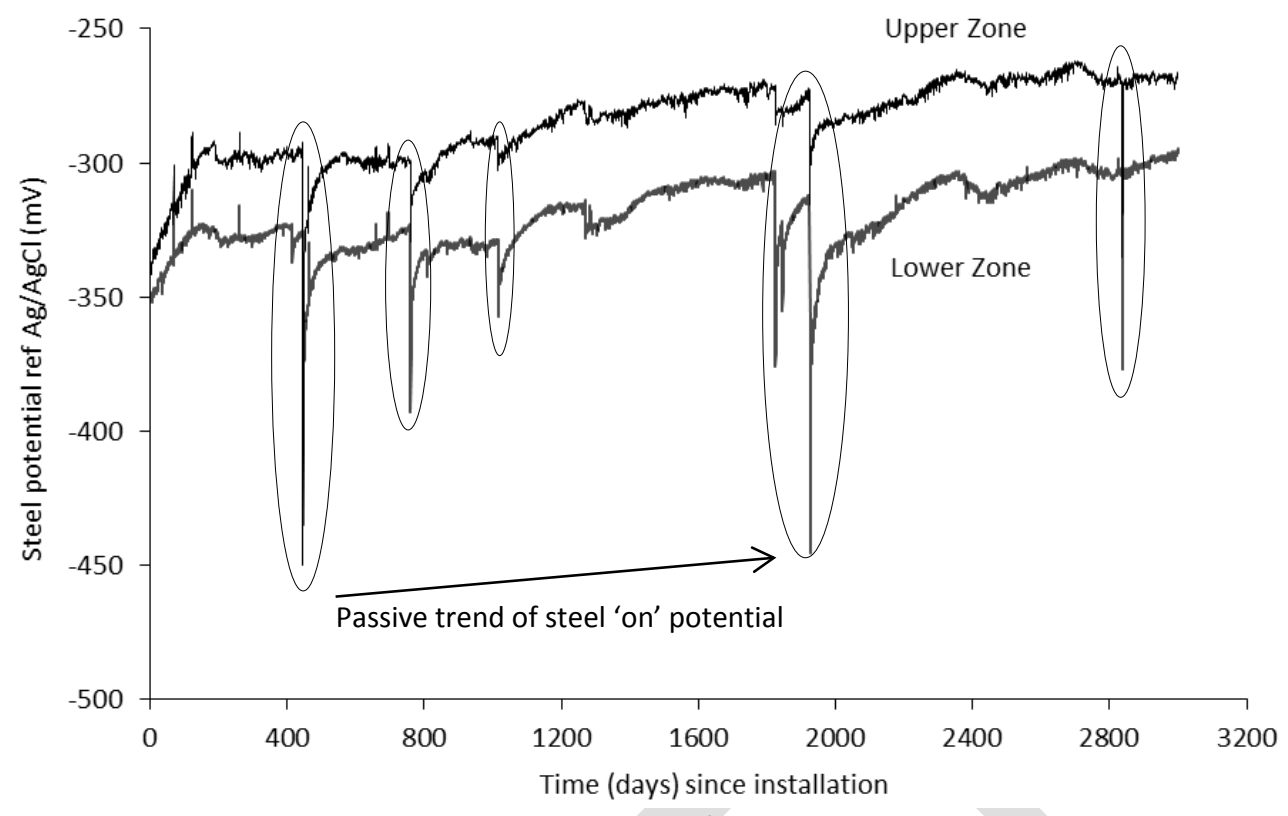

Figure 6 - Whiteadder, evolution of steel potential over time

System (c): Long-term monitoring data is not available for this structure as no remote monitoring equipment was installed at the bridge. The corrosion rate was calculated from a site visit on 23/05/2015 which indicates passive steel conditions for all four of the monitoring zones in the North abutment (Table 3 ).

Table 3 - Storth Lane, calculated corrosion rates

\begin{tabular}{|l|c|c|c|c|}
\hline Monitoring Zone & 1 & 2 & 3 & 4 \\
\hline 'On' potential (mV) & -442 & -344 & -466 & -472 \\
\hline Zone current $(\mathrm{mA})$ & 0.22 & 0.03 & 0.53 & 0.30 \\
\hline Anode driving voltage $(\mathrm{mV})$ & 223 & 381 & 272 & 191 \\
\hline 'Off' potential (1 hour) $(\mathrm{mV})$ & -436 & -343 & -450 & -468 \\
\hline Total de-polarisation $(\mathrm{mV})$ & 6 & 1 & 16 & 4 \\
\hline Cathodic current density $\left(\mathrm{mA} / \mathrm{m}^{2}\right)$ & 0.22 & 0.03 & 0.53 & 0.30 \\
\hline Corrosion rate $\left(\mathrm{mA} / \mathrm{m}^{2}\right)$ & $\mathbf{0 . 9 5}$ & $\mathbf{0 . 7 8}$ & $\mathbf{0 . 8 5}$ & $\mathbf{1 . 9 5}$ \\
\hline
\end{tabular}

The system at Storth Lane has achieved the recommended criteria for passive steel conditions on the date of this inspection. Also, no visual defects were observed in the area of influence of the hybrid anode zone during the inspection.

Although there is no substantial historical data with regards to the performance of system (c), the testing data suggest that there is no corrosion risk and the reinforcement may be considered to be in a benign environment.

System (d): This particular system does not have a continuous data monitoring system; however, manual readings are taken on an annual basis and these are presented in Figures 7 and 8 . Overall, it can be observed that the corrosion rates have generally remained below the recommended threshold value, apart from a single occurrence. The latter is not considered significant as it was a single event and the magnitude of increase is negligible. 


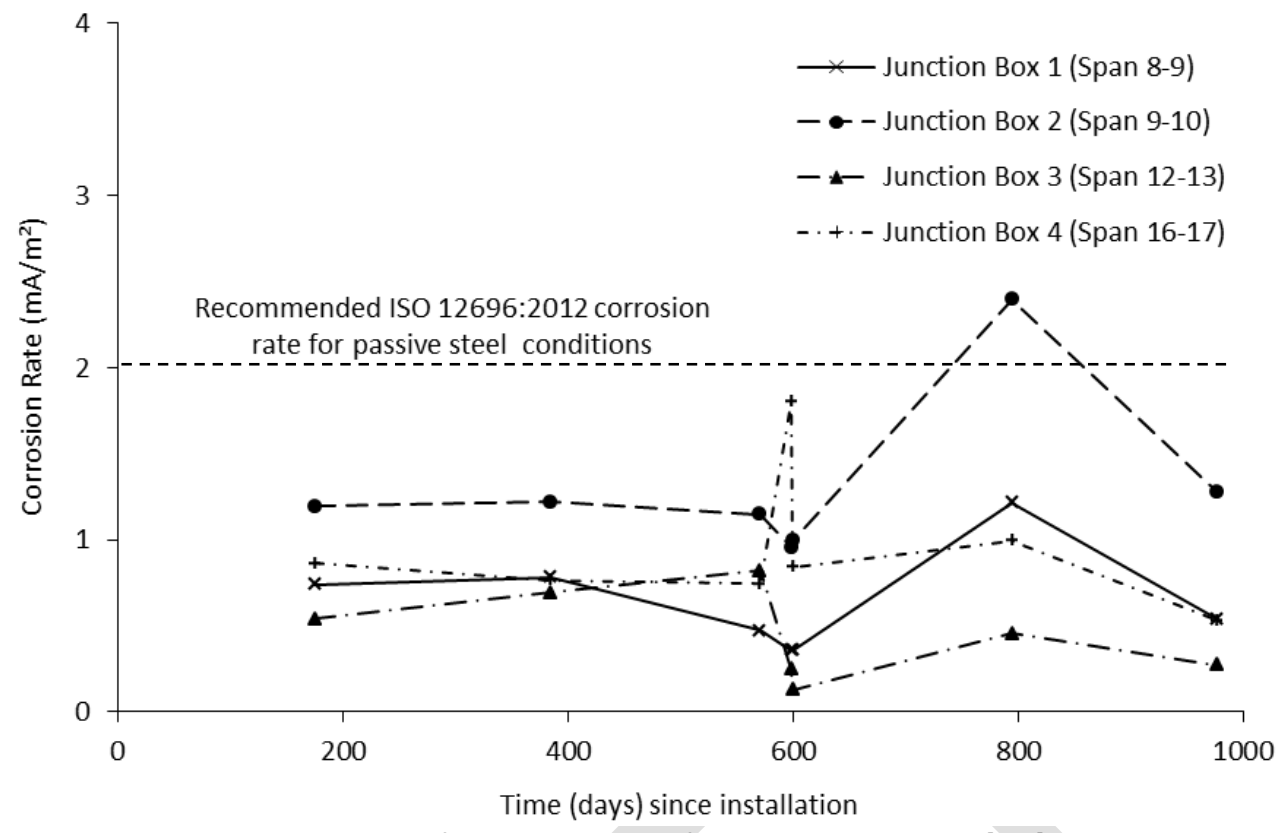

Figure 7 - Kyle of Tongue, evolution of corrosion rate with time [7, 8]

Furthermore, the open circuit steel potentials demonstrate a trend towards more positive values which also suggests that the reinforcement is protected and in a passive and benign environment.

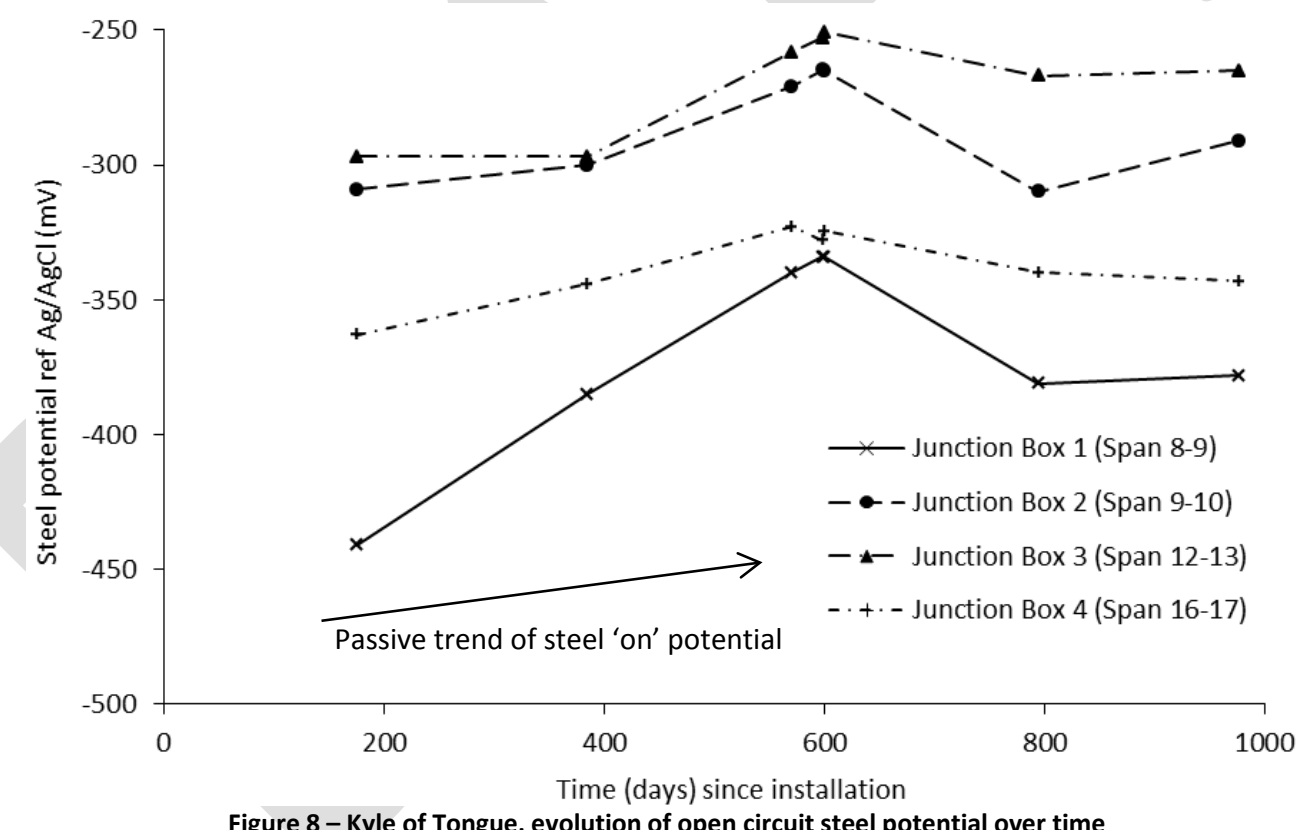

System (e): Long-term monitoring data was not available for this structure as no remote monitoring equipment was installed on the bridge. Furthermore, due to a 20 minute access limit (without specialist traffic management) it has not been possible to collect full depolarisation data from this bridge. The data collected during a site visit on 23/05/2014 shows that the monitored anode zones were effectively distributing a protective current to the steel reinforcement (Table 4). An extended depolarisation test would be beneficial in providing additional performance information and would enable a proper evaluation of the corrosion risk.

The higher corrosion current on the left zone of abutment 3 (Huncote) may be attributed to wetting of the abutment from the carriageway above, as noted in the visual inspection results. In addition, it has not been possible to undertake a complete depolarisation which may have yielded even lower corrosion current densities. 
Table 4 - M69 Junction 2, recorded site data

\begin{tabular}{|c|c|c|c|c|c|c|}
\hline Abutment & \multicolumn{2}{|c|}{1 (Junction 2) } & \multicolumn{2}{|c|}{2 (Junction 2) } & \multicolumn{2}{|c|}{3 (Huncote) } \\
\hline Zone & Left & Right & Left & Right & Left & Right \\
\hline ‘On' potential (mV) & -365 & -322 & -361 & -372 & -414 & -510 \\
\hline Monitoring zone current (mA) & 0.50 & 0.47 & 0.46 & 0.36 & 1.80 & 0.20 \\
\hline Remaining anodes current (mA) & 0.50 & 1.60 & 2.43 & 0.90 & 0.66 & 0.66 \\
\hline Monitoring zone driving voltage (mV) & 191 & 232 & 222 & 198 & - & - \\
\hline Anode driving voltage $(\mathrm{mV})$ & 223 & 214 & 214 & 177 & 247 & 220 \\
\hline Corrosion current density $\left(\mathrm{mA} / \mathrm{m}^{2}\right)$ & 0.67 & 0.63 & 0.61 & 0.48 & 2.40 & 0.27 \\
\hline
\end{tabular}

System (f): Long-term monitoring data was not available for this structure as no remote monitoring equipment was installed at the bridge. The corrosion rates calculated from the site visit on 09/01/2014 indicated passive steel conditions for all 16 monitoring zones tested (Tables 5 and 6). It has also been reported in previous commissioning reports (dated March 2013 and January 2014) that the hybrid system is performing effectively $[21,22]$.

Table 5 - Paston Interchange West piers, calculated corrosion rates

\begin{tabular}{|c|c|c|c|c|c|c|c|c|}
\hline \multirow[b]{3}{*}{ Zone } & \multicolumn{4}{|c|}{ North West Pier } & \multicolumn{4}{|c|}{ South West Pier } \\
\hline & \multicolumn{2}{|c|}{ Traffic Face } & \multicolumn{2}{|c|}{ Verge Face } & \multicolumn{2}{|c|}{ Traffic Face } & \multicolumn{2}{|c|}{ Verge Face } \\
\hline & 1 & 2 & 1 & 2 & 1 & 2 & 1 & 2 \\
\hline ‘On’ potential (mV) & -385 & -400 & -309 & -418 & -410 & -386 & -375 & -384 \\
\hline Monitoring zone current (mA) & 0.12 & 0.54 & 0.01 & 2.67 & 0.73 & 0.91 & 1.00 & 0.11 \\
\hline Remaining anodes current (mA) & \multicolumn{2}{|c|}{34.4} & \multicolumn{2}{|c|}{25.0} & \multicolumn{2}{|c|}{31.2} & \multicolumn{2}{|c|}{42.7} \\
\hline Instant 'off' potential (mV) & -385 & -400 & -308 & -418 & -408 & -384 & -374 & -383 \\
\hline Depolarised steel potential (mV) & -367 & -343 & -302 & -327 & -302 & -317 & -335 & -337 \\
\hline Total de-polarisation $(\mathrm{mV})$ & 18 & 57 & 6 & 91 & 106 & 67 & 39 & 46 \\
\hline Total de-polarisation time (Hours) & \multicolumn{2}{|c|}{26.0} & \multicolumn{2}{|c|}{26.4} & \multicolumn{2}{|c|}{25.8} & \multicolumn{2}{|c|}{25.2} \\
\hline Cathodic current density $\left(\mathrm{mA} / \mathrm{m}^{2}\right)$ & 0.56 & 0.56 & 0.40 & 0.40 & 0.50 & 0.50 & 0.69 & 0.69 \\
\hline Corrosion rate $\left(\mathrm{mA} / \mathrm{m}^{2}\right)$ & 0.79 & 0.21 & 1.73 & 0.07 & 0.07 & 0.15 & 0.42 & 0.34 \\
\hline
\end{tabular}

Table 6 - Paston Interchange East piers, calculated corrosion rates

\begin{tabular}{l} 
Table 6- Paston Interchange East piers, calculated corrosion rates \\
\cline { 2 - 12 }
\end{tabular}

The low corrosion rates for all 16 monitoring zones, combined with relatively low changes in steel potential between the 'on' and 'off' readings (i.e. the total de-polarisation over 24 hours) suggest that corrosion activity is minimal. This structure therefore has a low risk of corrosion initiation.

\section{DISCUSSION}

The aim of this study was to conduct the first independent appraisal of the effectiveness of hybrid anode systems at preventing corrosion initiation of the reinforcing steel using the holistic approach of a condition and corrosion risk assessment. This approach combined the absolute values and alternative performance criteria in 
ISO 12696:2012 [18], together with an assessment of the overall corrosion risk to a structure from the results of a visual inspection, calculated equivalent section loss of the reinforcing steel over time, and the trends of long term monitoring data.

Overall, the results of the visual inspections indicated that the areas protected by the hybrid anode systems were found to have no visual defects, and the structures were generally in a good condition. The most common observation was the ingress of water from the carriageways above, due to leaking bridge joints. Using the approach of a holistic corrosion risk assessment, all of the structures were found to have a low associated corrosion risk.

Overall, there have been instances where the measured corrosion rates were somewhat higher than the recommended threshold values. While on face value this may appear to be a system failure it ought to be reviewed in overall context. In particular, all instances where a corrosion rate higher than the recommended threshold was calculated, it was observed that the steel 'on' potentials had shifted over time towards more positive values. In addition, all the current outputs were relatively low, with no physical evidence suggesting corrosion (e.g. rust staining, cracking, delamination etc.). All of these, suggest a benign environment with passive reinforcement.

In addition, by undertaking a simple mathematical sensitivity analysis of the Butler-Volmer equation for corrosion rate assessment it is evident that where there are only very small potential shifts, then the equation can return high corrosion rates which should not necessarily be related with high corrosion risk. In fact, this investigation has demonstrated that there is sufficient evidence from a number of structures which had continuous monitoring of steel potentials to indicate that the higher corrosion rates observed at instances are not necessarily realistic.

In particular, a monitoring area comprising of $0.68 \mathrm{~m}^{2}$ of steel reinforcement, can yield a corrosion current density of $2.4 \mathrm{~mA} / \mathrm{m}^{2}$ based on an output anode current of $0.25 \mathrm{~mA}$ and a potential shift $(\Delta \mathrm{E})$ of $4 \mathrm{mV}$. However, the very same zone will result in a corrosion current density of $1.28 \mathrm{~mA} / \mathrm{m}^{2}$ based on an output anode current of $0.1 \mathrm{~mA}$ and a potential shift $(\Delta \mathrm{E})$ of $3 \mathrm{mV}$. This demonstrates the overall sensitivity of the equation when dealing with very small currents and potential shifts.

The collected data shows that the corrosion rates generally remained below the $2 \mathrm{~mA} / \mathrm{m}^{2}$ threshold recommended by ISO 12696:2012, which indicates passive steel conditions [18, 19]. In most of the applications, low magnitude corrosion rates had been calculated over a period of 8 years since the installation of the hybrid systems. In some isolated cases, the corrosion rate exceeded the recommended threshold; however, this does not necessarily indicate a non-compliant or unsatisfactory system. The highest observed corrosion rate was $3.5 \mathrm{~mA} / \mathrm{m}^{2}$, which equates to an equivalent section loss of reinforcing steel of $3.5 \mathrm{~mm}$ over 1000 years. If this is compared against a typical 120 year design life for a bridge structure then a section loss of approximately $0.4-0.5 \mathrm{~mm}$ should be expected. The trends in steel 'on' potential for these structures also confirmed the low risk of corrosion as the reinforcing steel is becoming more passive. The resting steel 'on' potentials for systems (a), (b) and (d) have shifted positively by approximately $150-200 \mathrm{mV}, 40-50 \mathrm{mV}$ and 20 $60 \mathrm{mV}$ respectively.

Where remote monitoring is available, extensive site data can be collected and the ongoing performance of hybrid systems can be assessed without the need for site visits, access, or traffic management. Data logging equipment can be programmed to automatically record depolarisation readings at regular intervals, which can be used to plot the change in depolarised steel potential readings and corrosion rates over time. This data is useful when assessing the performance of hybrid anode systems and subsequent corrosion risk $[6,18]$.

The data analysed in this study indicates that the design approach of an initial impressed current phase (50kC), followed by an ongoing galvanic phase for the remainder of the anodes design life, has been effective at preventing the initiation of reinforcement corrosion for up to about 8 years. This agrees with the majority of published work on the performance of hybrid anode systems and is a positive finding for the implementation of hybrid anodes as an alternative corrosion risk management technique in reinforced concrete structures [6, 9-16]. 


\section{DESIGN RECOMMENDATIONS}

As part of the independent appraisal, the following recommendations should be considered when designing new hybrid anode systems, primarily to improve the redundancy, functionality and robustness of the system. These have been based partly on the data obtained as part of this study, together with the experience of the authors in the design, installation and monitoring of hybrid anode systems in reinforced concrete structures.

It would be beneficial to obtain long-term monitoring data for all new systems, which would enable an assessment of the continued performance of the hybrid system, similar to the data provided for systems (a), (b) and (d) in this study. This should include the installation of reference electrodes in areas of high corrosion risk, and junction boxes for enclosing monitoring equipment. Remote monitoring is particularly useful at sites with limited access, or where traffic management (which can be disruptive and costly) is required. It is also important to position junction boxes in suitable locations on the structure, away from the risk of surface water run-off and potential vandalism and theft.

To improve redundancy within the hybrid systems, it is recommended that a titanium terminated copper cable (300 mm titanium wire crimped and sealed to a length copper cable at each end) be introduced, connecting the first anode within the treatment zone to the junction box location. This would be an extra connection in addition to the usual titanium feeder wire. The copper cable significantly reduces the voltage drop when long distances of feeder wire have to be installed between treatment zones and monitoring equipment. The titanium termination of the copper cable at both ends enables a better connection to the terminals in the junction box and also prevents corrosion initiation at the point of connection.

\section{CONCLUSIONS}

It can be concluded that:

- The six structures were found to be generally in good condition, 1 to 8 years after refurbishment works;

- The areas of reinforced concrete protected by the hybrid anode technology were found to have no visual defects associated;

- The results of depolarisation tests suggest that the hybrid anodes are effectively protecting the steel reinforcement, which is considered to be in a passive condition;

- In the majority of cases, the calculated corrosion rates as set out in ISO 12696:2012 were below the recommended threshold of $2 \mathrm{~mA} / \mathrm{m}^{2}$ for passive reinforcement;

- On some occasions the corrosion rate exceeded the recommended threshold; however, the structures were still assessed as a low corrosion risk based on the absence of any visual defects, open circuit steel potential trending towards positive values and the fact that the recommend corrosion rate was exceeded in single and isolated events. The calculated corrosion rate was only marginally higher than the recommended threshold; all of which provide reassurance of a resultant low corrosion risk;

These conclusions highlight that the design approach to hybrid anode systems to achieve their intended design life is effective. This is a positive finding for implementing hybrid anodes as a corrosion management technique in reinforced concrete structures. This study was the first of its kind to adopt a new method of assessment for hybrid anode systems using a holistic approach to corrosion risk assessment, rather than focusing primarily on absolute values stated in ISO 12696:2012 [18].

\section{REFERENCES}

[1] Stratfull, R.F. 1957. The corrosion of steel in a reinforced concrete bridge. Corrosion, Volume 13, No. 3, pp. 43-48.

[2] Stratfull, R.F. 1974. Cathodic protection of a bridge deck. Materials Performance, Volume 13, No. 4, pp 24-36.

[3] Davy, H. 1824. On the corrosion of copper sheeting by seawater, and on methods of preventing this effect, and on their application to ships of war and other ships. Philosophical Transactions of the Royal Society, Volume 114, pp 151-246.

[4] Glass, G.K. Roberts, A.C. Davison, N. 2008. Hybrid corrosion protection of chloride-contaminated concrete. Construction Materials, Volume 161, pp. 163-172.

[5] Holmes, S.P. Wilcox, G.D. Robins, P.J. Glass, G.K. Roberts, A.C. 2011. Long term assessment of a hybrid electrochemical treatment. Materials and Corrosion, Volume 62, No. 9999, 7 pp.

[6] Glass, G. Christodoulou, C. Holmes, S. 2012. Protection of steel in concrete using galvanic and hybrid electrochemical treatments. In: Alexander, M.G. Beushausen, H.D. Dehn, F. Moyo, P. (eds). 2012. Concrete Repair, Rehabilitation and Retrofitting III: 3rd International Conference on Concrete Repair, Rehabilitation and Retrofitting, ICCRRR-3, 3-5 September 2012, Cape Town, South Africa. pp. 523-526. Taylor and Francis Group. 
[7] Christodoulou, C. Goodier, C. Austin, S. Webb, J. Glass, G. 2013. Hybrid corrosion protection of a prestressed concrete bridge. European Corrosion Conference 2013, EUROCORR 2013, Estoril, Portugal, 1st-5th September 2013, https://dspace.lboro.ac.uk/2134/13191.

[8] Christodoulou, C. Kilgour, R. 2013. The world's first hybrid corrosion protection systems for prestressed concrete bridges. Corrosion \& Prevention 2013, Australasian Corrosion Association, Brisbane, Australia, 10th-13th November 2013, paper 076, 11pp.

[9] Glass, G.K. Buenfeld, N.R. 1995. On the current density required to protect steel in atmospherically exposed concrete structures. Corrosion Science, Volume 37, pp. 1643-1646.

[10] Polder, R.B. Peelen, W.H.A. Stoop, B.T.J. Neeft, E.A.C. 2009. Early stage beneficial effects of cathodic protection in concrete structures, EUROCORR 2009, Paper 8408.

[11] Glass, G.K. Roberts, A.C. Davison, N. 2004. Achieving high chloride threshold levels on steel in concrete. Corrosion 2004, NACE, Paper No. 04332.

[12] Glass, G.K. Reddy, B. Clark, L.A. 2007. Making reinforced concrete immune to chloride corrosion. Proceedings of the ICE, Construction Materials, Volume 160 (4), pp. 155-164.

[13] Holmes, S.P. Wilcox, G.D. Robins, P.J. Glass, G.K. Roberts, A.C. 2011. Responsive behavior of galvanic anodes in concrete and the basis for its utilisation. Corrosion Science, Volume 53, pp. 3450-3454.

[14] Holmes, S.P. Christodoulou, C. Glass, G.K. 2013. Monitoring the passivity of steel subject to galvanic protection. Corrosion \& Prevention 2013, Australasian Corrosion Association, Brisbane, Australia, 10th-13 ${ }^{\text {th }}$ November 2013, paper 133. 11pp.

[15] Christodoulou, C. Goodier, C.I. Austin, S.A. Glass, G.K. Webb, J. 2014. A new arrangement of galvanic anodes for the repair of reinforced concrete structures, Construction \& Building Materials, Volume 50, pp. 300-307, https://dspace.lboro.ac.uk/2134/13593, http://dx.doi.org/10.1016/j.conbuildmat.2013.09.062.

[16] Dodds, W. Christodoulou, C. Goodier, C.I. Austin, S.A. 2014. Performance evaluation of galvanic anodes through laboratory testing and on-site monitoring. RILEM International workshop on performance-based specification and control of concrete durability, $11-13^{\text {th }}$ June 2014, Zagreb, Croatia, pp. 175-182, ISBN 978-2-35158-135-3, https://dspace.lboro.ac.uk/2134/15296..

[17] CPT Ltd. 2014. The DuoGuard ${ }^{T M}$ Hybrid Anode ${ }^{T M}$ range installation guidelines, Revision 6. 8pp.

[18] British Standards Institution, 2012. BS EN ISO 12696:2012, Cathodic protection of steel in concrete, London: BSI.

[19] Christodoulou, C. Glass, G. Webb, J. Austin, S, Goodier, C. 2010. Assessing the long term benefits of Impressed Current Cathodic Protection. Corrosion Science, Volume 52, Issue 8, pp. 2671-2679, doi:10.1016/j.corsci.2010.04.018, http://hdl.handle.net/2134/7674.

[20] Hassanein, A.M. Glass, G.K. Buenfeld, N.R. 2002. Protection current distribution in reinforced concrete cathodic protection systems. Cement \& Concrete Composites, Volume 24, pp. 159-167.

[21] Edwards, R. 2013. A47 Peterborough Interchange Phase 3 - Hybrid anode cathodic protection system, commissioning report, Technical Report CN12-019-TR0022, Corrosion Engineering Solutions Ltd.

[22] Holmes, S. 2014. Hybrid cathodic protection review - Paston Interchange, Monitoring visit report CPT270114A, Concrete Preservation Technologies Ltd. 